\title{
Fluids in ARDS: more pros than cons
}

\author{
Renata de S. Mendes ${ }^{1}$, Paolo Pelosi ${ }^{2,3}$, Marcus J. Schultz ${ }^{4,5,6}$, Patricia R. M. Rocco ${ }^{1+}$ and Pedro L. Silva ${ }^{1 *+}$ (D) \\ From 4th International Symposium on Acute Pulmonary Injury and Translational Research - INSPIRES 2019 \\ Dresden, Germany. 25-26 November 2019
}

\author{
*Correspondence: pedro.leme@ \\ gmail.com; pedroleme@biof.ufrj.br \\ ${ }^{\dagger}$ Dr. Rocco and Dr. Silva share senior \\ authorship. \\ 'Laboratory of Pulmonary \\ Investigation, Carlos Chagas Filho \\ Biophysics Institute, Federal \\ University of Rio de Janeiro, Centro \\ de Ciências da Saúde, Avenida \\ Carlos Chagas Filho, s/n, Bloco \\ G-014, llha do Fundão, Rio de \\ Janeiro, RJ 21941-902, Brazil \\ Full list of author information is \\ available at the end of the article
}

\begin{abstract}
In acute respiratory distress syndrome (ARDS), increased pulmonary vascular permeability makes the lung vulnerable to edema. The use of conservative as compared to liberal fluid strategies may increase the number of ventilator-free days and survival, as well as reduce organ dysfunction. Monitoring the effects of fluid administration is of the utmost importance; dynamic indexes, such as stroke volume and pulse pressure variations, outperform static ones, such as the central venous pressure. The passive leg raise and end-expiratory occlusion tests are recommended for guiding fluid management decisions. The type of intravenous fluids should also be taken into consideration: crystalloids, colloids, and human albumin have all been used for fluid resuscitation. Recent studies have also shown differences in outcome between balanced and non-balanced intravenous solutions. In preclinical studies, infusion of albumin promotes maintenance of the glycocalyx layer, reduces inflammation, and improves alveolar-capillary membrane permeability. Fluids in ARDS must be administered cautiously, considering hemodynamic and perfusion status, oncotic and hydrostatic pressures, ARDS severity, fluid type, volume and infusion rate, and cardiac and renal function. Of note, no guideline to date has recommended a specific fluid composition for use in ARDS; most physicians currently follow recommendations for sepsis.
\end{abstract}

Keywords: Acute respiratory distress syndrome, Balanced solution, Non-balanced solutions, Colloids, Human albumin, Hemodynamic

\section{Background}

Acute respiratory distress syndrome (ARDS) is a multifactorial syndrome caused by different etiologies, which can be pulmonary or extrapulmonary [1]. A major feature of ARDS is increased pulmonary vascular permeability [2]; consequently, interstitial and alveolar edema are hallmarks of its pathophysiology. In addition, lung inflammation, damage to epithelial and endothelial cells, disruption of the extracellular matrix [3], and coagulation disturbances [4] have been recognized.

Mitigating lung edema, accelerating its resorption, and maintaining systemic perfusion and distal organ function through modulation of fluid intake seem to be beneficial in ARDS. Several issues should be considered during fluid infusion in this patient population: (1) the etiology, severity, and phase of ARDS; (2) static and dynamic

(c) The Author(s). 2020 Open Access This article is licensed under a Creative Commons Attribution 4.0 International License, which permits use, sharing, adaptation, distribution and reproduction in any medium or format, as long as you give appropriate credit to the original author(s) and the source, provide a link to the Creative Commons licence, and indicate if changes were made. The images or other third party material in this article are included in the article's Creative Commons licence, unless indicated otherwise in a credit line to the material. If material is not included in the article's Creative Commons licence and your intended use is not permitted by statutory regulation or exceeds the permitted use, you will need to obtain permission directly from the copyright holder. To view a copy of this licence, visit http://creativecommons.org/licenses/by/4.0/. 
methods to monitor fluid administration; (3) the type of fluids (crystalloids versus colloids, balanced versus non-balanced solution); and, (4) if albumin is used, its concentration. The present review will discuss recent studies on different fluid types and strategies and their effects on the aforementioned aspects of ARDS.

\section{Importance of ARDS pathophysiology when choosing the amount and type of fluids}

Early ARDS is characterized by increased alveolar-capillary barrier damage, which results in lung edema, as well as reduced peripheral perfusion [4]. Increased lung water content impairs lung mechanics and gas exchange, leading to hypoxemia and increased risk of pulmonary arterial hypertension. Moreover, the presence of lung edema perpetuates lung inflammation and epithelial cell damage, thus reducing surfactant production and hindering edema reabsorption $[4,5]$.

Choosing the optimal fluid strategy (both regarding quantity and type of fluid) is one of the greatest clinical challenges in ARDS management, since both impaired hemodynamics and electrolyte disturbances must be corrected $[6,7]$, but either one may exacerbate pulmonary edema.

Starling's classic model states that transvascular fluid exchange depends on a balance between hydrostatic and oncotic pressure gradients (Fig. 1) [8]. However, this theory has been considered inconsistent with our new understanding of the role of the glycocalyx [9]. It is now known that the interstitial space has a high protein concentration [8], which weakens the concept of fluid flow direction being guided solely by the difference in capillary and interstitial oncotic pressures. On the other hand, the subglycocalyx space is also responsible for oncotic pressure gradients (Osg) that may determine

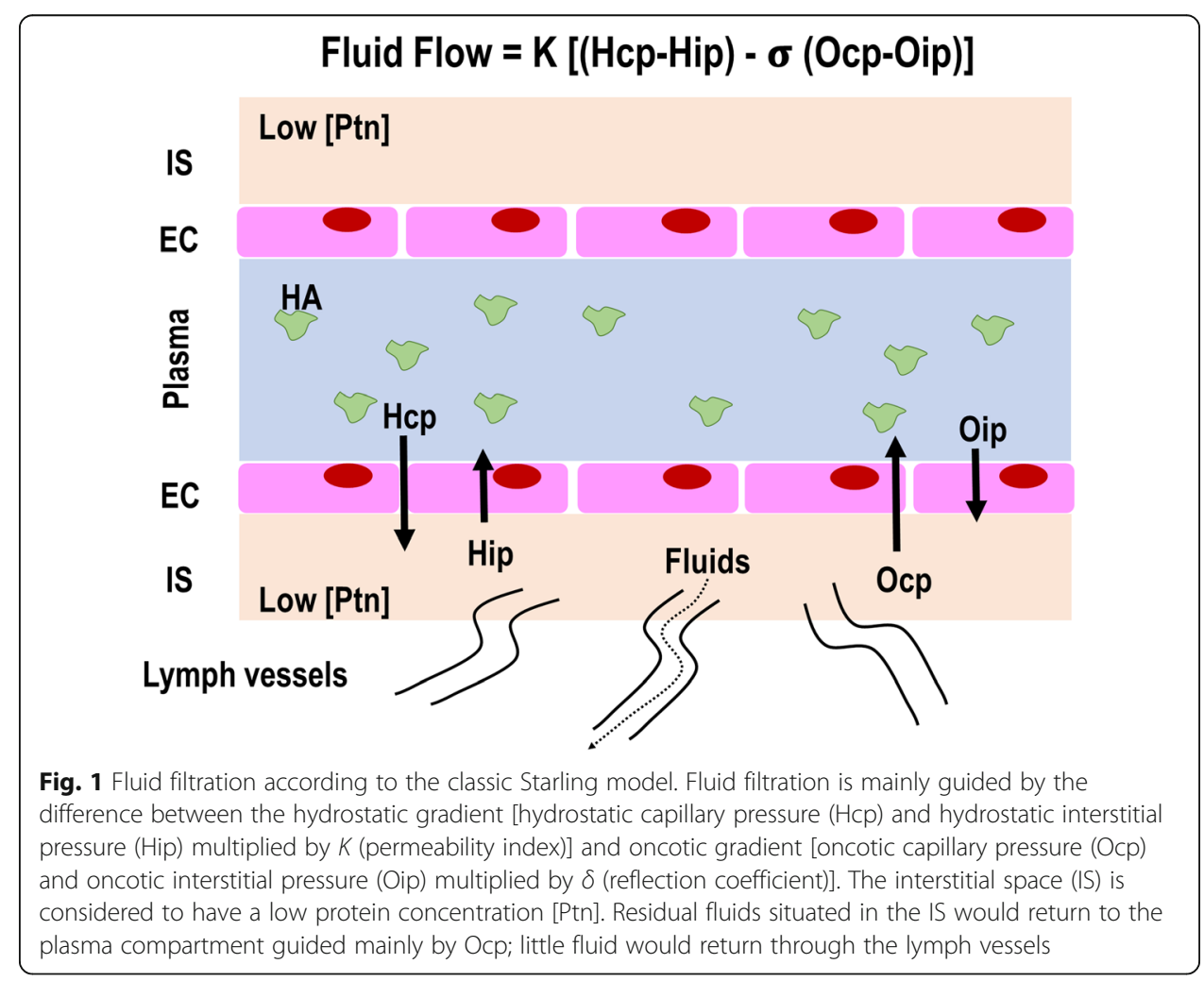


the transcapillary flow. The functional barrier created by the endothelial glycocalyx layer-which is composed of a glycoprotein skeleton, proteoglycans, and interactions with circulating cells and plasma constituents, including albumin-forms an endothelial surface up to $1 \mu \mathrm{m}$ thick [8]. The luminal side of the endothelium, below this "protein sponge," is permanently removed through small breaks (clefts) in the intercellular junction chains to adjacent tissues [10], thus creating an inwardly directed oncotic force (Oip), quantitatively opposed to hydrostatically (Hcp) driven fluid filtration (Fig. 2). Lymph vessels are responsible for the return of fluid to the circulation, which is regulated through sympathetically mediated responses [8]. Although albumin infusion may improve or maintain vascular barrier competence, experiments with isolated organs show that the surface functions well until the albumin concentration falls below $10 \mathrm{~g} / \mathrm{L}$ [11]. Therefore, it is very likely that the major insult to the vascular barrier leading to its dysfunction is not hypoalbuminemia, but damage to the endothelial glycocalyx. Several factors are associated with glycocalyx damage, such as hypervolemia [12], rapid crystalloid infusion [13], ischemia-reperfusion [14], inflammation [8], sepsis [15], hyperglycemia [16], trauma [17], and altered plasma $\mathrm{pH}$ [18]. The glycocalyx is the first and the primary source of resistance to the stream of fluid and solutes between plasma and lymph. Compaction of endothelial glycocalyx and the consequent increase in levels of glycosaminoglycans (GAGs-heparan, hyaluronic acid, or chondroitin) in plasma are considered markers of glycocalyx injury [19,20]. In this context, circulating levels of syndecan-1 and GAGs have been found elevated in septic patients [15, 21, 22] and are associated with disease severity and worse outcomes [21].

\section{Fluid volume and monitoring in ARDS patients}

Conservative fluid replacement strategies have been recommended to prevent lung edema. These strategies are associated with less invasive mechanical ventilation, less organ dysfunction, and a trend toward less renal replacement therapy [6, 23]. A recent systematic review and meta-analysis showed that conservative or deresuscitative fluid

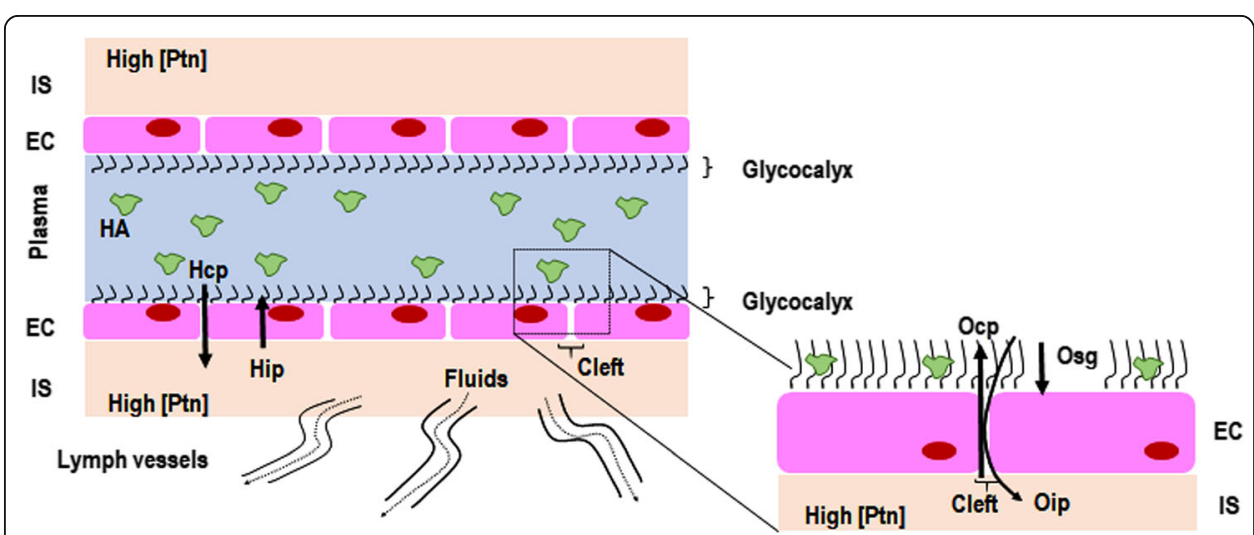

Fig. 2 New fluid filtration model. This model proposes that the glycocalyx, which is composed of a glycoprotein skeleton and proteoglycans, interacts with circulating cells and plasma constituents (including albumin) to form an endothelial surface up to $1 \mu \mathrm{m}$ thick. The interstitial space is considered to have a high protein concentration (Ptn) and, thus, a high oncotic interstitial pressure (Oip), which decreases fluid return to the plasma compartment. Additionally, due to the retention of human albumin molecules in the glycocalyx layer, this structure may generate its own oncotic pressure (Osg), which further jeopardizes fluid return to the plasma compartment. The residual fluid volume in the IS in this model is much greater than in the classic Starling model, and excess fluid may return through the lymph vessels 
strategies resulted in an increased number of ventilator-free days and a decreased length of ICU stay compared with a liberal strategy or standard care in adults and children with ARDS, sepsis, or systemic inflammatory response syndrome. Nevertheless, the effect on mortality remains uncertain [6]. In an attempt to better identify those patients who would benefit from fluid replacement, aldosterone and B-type natriuretic peptide (BNP) have been assessed as possible outcome predictors. The authors found that lower levels of aldosterone seem to identify ARDS patients for whom conservative fluid management may improve mortality, while BNP levels did not predict outcomes [24]. In a recent study, conservative fluid management was found to improve mortality in black patients with ARDS [25], suggesting that fluid strategies may be personalized in the future.

\section{Hemodynamic monitoring}

To date, no ideal method has been developed to continuously monitor the response to fluid replacement in ARDS. Four questions have been described to guide fluid strategy in patients with septic shock: "When to start intravenous fluids?", "When to stop intravenous fluids?", "When to start de-resuscitation or active fluid removal?", and, finally, "When to stop de-resuscitation?" [7]. These questions are also pertinent when dealing with non-sepsis states [7]. Several tests and devices are available to predict fluid responsiveness [26]. Static markers of cardiac preload, such as central venous pressure (CVP), do not reliably predict fluid responsiveness; dynamic indexes should be used instead [27].

\section{Dynamic indexes to predict fluid responsiveness}

\section{The passive leg raise test}

The passive leg raise test (PLR) [28] consists of moving a patient from the semirecumbent position to a position where the legs are lifted at $45^{\circ}$ and the trunk is horizontal. The transfer of venous blood from the lower limbs and the splanchnic compartment toward the cardiac cavities mimics the increase in cardiac preload induced by a fluid bolus of roughly $300 \mathrm{ml}$ [28]. This test is able to predict fluid responsiveness [29]; the threshold to define responsiveness is a $10 \%$ increase in stroke volume and/or cardiac output (CO) after PLR.

\section{Stroke volume variation (SVV) and pulse pressure variation (PPV)}

SVV and PPV, derived from the arterial pressure signal, represent the influence of the periodic increase in intrathoracic pressure due to invasive mechanical ventilation. For SVV and PPV to be accurate predictors of fluid responsiveness, at least four conditions are necessary: sedation and paralysis, tidal volume $\left(V_{\mathrm{T}}\right) \geq 8 \mathrm{ml} / \mathrm{kg}$, regular heart rhythm, and respiratory system compliance $\geq 30 \mathrm{ml} / \mathrm{cm} \mathrm{H}_{2} \mathrm{O}$ [30,31]. Several studies have shown that an SVV greater than $10 \%$ or a PPV greater than $13-15 \%$ are predictive of fluid responsiveness [32].

\section{The end-expiratory occlusion (EEO) test}

The EEO test is easy to perform in patients under invasive mechanical ventilation [33]. Ventilation is briefly interrupted (15-30 s), which increases the right cardiac preload to 
its maximum value. Depending on the duration of occlusion, transmission occurs to the left side. An increase in stroke volume is indicative of preload responsiveness [33]. The EEO test proved reliable in several settings [34,35], especially when $V_{\mathrm{T}} \geq 8 \mathrm{ml} / \mathrm{kg}$, but not with $V_{\mathrm{T}}=6 \mathrm{ml} / \mathrm{kg}$ [36]. Therefore, caution is warranted in the use of the test, since a protective tidal volume is always recommended in ARDS. EEO may predict fluid responsiveness even in prone position and during the Trendelenburg maneuver [37].

\section{Types of fluids in ARDS}

It is well established that, due to the potential impact on alveolar-capillary membrane damage and lung edema, the type of fluid infused may influence ARDS outcome [38, 39]. However, there is no consensus to date regarding the best fluid for use in ARDS.

\section{Crystalloids versus colloids}

The ALBIOS trial study evaluated 1818 critically ill patients and randomized them to two types of replacement fluid: $20 \%$ albumin plus crystalloid or crystalloid only. In the intervention group, the goal of therapy was to achieve plasma albumin levels $>30 \mathrm{~g} / \mathrm{L}$. There was no difference in overall mortality at 28 days. An ongoing trial (NCT03869385) was designed to assess the impact of $20 \%$ albumin with crystalloid with a target albumin level of $>30 \mathrm{~g} / \mathrm{L}$ in patients with septic shock, with 28-day mortality as the primary endpoint. Another ongoing clinical trial (NCT03654001) is comparing 20\% albumin plus balanced solutions, 20\% albumin plus saline, and balanced solutions alone in septic shock. No clinical trial has evaluated albumin or other types of fluids specifically in ARDS, and none is ongoing.

\section{Balanced versus non-balanced}

Crystalloids can also be categorized as balanced or non-balanced (unbalanced) solutions. Balanced solutions contain a precursor anion of bicarbonate in their composition: lactate in Ringer's lactate, acetate in Ringer's acetate and Plasma-Lyte ${ }^{\circ}$, and others such as gluconate, malate, citrate, and succinate in less commonly used solutions [40]. Nonbalanced solutions (such as $0.9 \% \mathrm{NaCl}$ ) are unbuffered and have higher chloride content.

Balanced solutions provide some advantages, not least the choice of anion: they (1) replace bicarbonate, (2) are rapidly metabolized, (3) are nontoxic, and (4) maintain $\mathrm{pH}$ at $4-8$, minimizing hemolysis and endothelial cell damage in peripheral circulation [40]. However, some issues unique to each of the different anions used in balanced solutions must be taken into account before choosing one. For example, almost $70 \%$ of infused lactate will participate in gluconeogenesis, being converted to pyruvate and potentially destabilizing glycemic control [41]. Pyruvate follows the Krebs cycle via acetylcoA, generating carbon dioxide. If lactate accumulates, glycolysis is delayed at the glyceraldehyde-3-phosphate stage, thus reducing ATP generation [41]. On the other hand, acetate has certain theoretical advantages over lactate, as it is metabolized more rapidly (300 mmol/h) and completely (i.e., without accumulating). Acetate does not lead to hyperglycemia and has less effect on oxygen consumption and carbon dioxide elimination. Furthermore, unlike lactate, acetate is metabolized in various non-hepatic tissues, particularly muscle, so is less subject to accumulation in shock or liver dysfunction. The half-life of unbalanced solutions is longer than that of balanced 
solutions [42], which should be considered when choosing fluid type in different clinical scenarios. Finally, the higher chloride concentration of unbalanced solutions leads to reduced renal flow and increased renal injury [43, 44].

However, clinical studies comparing balanced versus unbalanced crystalloids in intensive care have shown conflicting results regarding renal outcomes and mortality [4448]. The SPLIT study randomized 2278 patients to receive Plasma-Lyte ${ }^{\bullet}$ versus $0.9 \%$ saline [47]. There was no difference in the proportion of patients with acute, moderate, or severe renal injury. (Nevertheless, it bears stressing that the SPLIT study enrolled patients at low risk of acute kidney injury and that the average volume of fluid infused was less than $2000 \mathrm{~mL}$ ). The SMART study randomized 15,802 patients to receive $0.9 \%$ saline versus balanced crystalloid (Ringer lactate or Plasma-Lyte ${ }^{\circ}$ ) in five intensive care units [49]. The authors showed an association between reduced risk of major renal effects (need for renal replacement therapy, death and/or creatinine at endpoint $>200 \%$ at admission) and the use of balanced solutions. In an emergency department setting, the SALT-ED study included non-critically ill patients and compared $0.9 \%$ saline versus ringer lactate or Plasma-Lyte ${ }^{\bullet}$ [50]. Although mortality at 28 days did not differ between groups, fewer renal adverse events were observed in the group receiving balanced solutions.

\section{Colloids}

Colloids are water-based solutions containing permeable ions and non-permeable molecules, which can be plasma-derived (albumin) or synthetic (gelatins, starches, and dextran) and are unable to cross intact semipermeable biological membranes. The intravascular duration of colloid-derived volume expansion depends on the rate of metabolism and clearance of its constituent molecules [51]. Colloid turnover is described according to the elimination half-life of the oncotic macromolecules contained in the fluid. The half-life of crystalloids is usually expressed in minutes, while elimination of colloids can take hours [42]. Importantly for clinical practice, these elimination halflives do not reflect the duration of plasma expansion, which is much shorter. This means that macromolecules persist for many hours outside the bloodstream, impregnating renal tissue and thus promoting osmotic nephrotic injury [52], urinary hyperviscosity (which causes tubular obstruction), and inflammation [53]. Synthetic colloids have a well-established association with severe adverse events [54]; human albumin remains under clinical evaluation in this respect.

\section{Albumin in ARDS}

Human albumin is commercially available in several concentrations: iso-oncotic (5\%) and hyper-oncotic (20\% and 25\%) [55]. However, few studies have compared these concentrations in terms of impact on clinical outcomes.

Albumin has many other properties in addition to its effects on intravascular volume, including antioxidant activities and molecular transport [55]. Clinical research has shown improvement in physiological parameters after human albumin administration with or without furosemide in patients with ARDS [56]. The antioxidant effect of albumin is related to its capacity to bind iron and copper, thus reducing the availability of these components for pro-oxidant reactions [57]. Changes in albumin concentration and structure during critical illness can lead to significant changes in homeostasis, 
metabolism, and drug distribution and efficacy [57]. Antimicrobial binding capacity has been shown to be decreased in patients with hypoalbuminemia [58]. These changes may result in inadequate treatment, particularly for time-dependent antibiotics, which may require dose adjustments [58]. Albumin can also protect the microvasculature and attenuate increased vascular permeability by reducing capillary bed leakage $[59,60]$. Finally, there is an inverse association of albumin concentration with levels of several pro-inflammatory cytokines [61].

Lung tissue endothelial VE-cadherin expression is reduced in ARDS [3]. In vitro studies have reported rupture of endothelial adherens junctions, corroborating this clinical finding [62]. Reduction of VE-cadherin expression has been associated with increased vascular permeability in ARDS [3] (Fig. 3a). In experimental ARDS, both iso- (4\%) and hyper-oncotic $(20 \%)$ human albumin preserved the integrity of the endothelial barrier compared to Ringer lactate [63], in a mechanism apparently mediated by reduced lung inflammation [64].

Activation of endothelial cells (by microorganisms, toxins, or ischemia-reperfusion injury) leads to the production of mediators (such as angiopoietin-2) and neutrophil infiltration, thus increasing lung vascular permeability. Neutrophil-mediated epithelial injury has been associated with multiple mechanisms: tumor necrosis factor (TNF)- $\alpha$, neutrophil extracellular traps (NETs), and TNF-related apoptosis-inducing ligand (TRAIL) $[65,66]$. In preclinical ARDS studies, albumin attenuated lung damage by reducing oxidative stress and pulmonary inflammation [38, 39, 63]. However, in vitro [67] and in vivo [68] studies reported that hyper-oncotic albumin (20-25\%) was associated with renal dysfunction proportional to its concentration. Accordingly, in
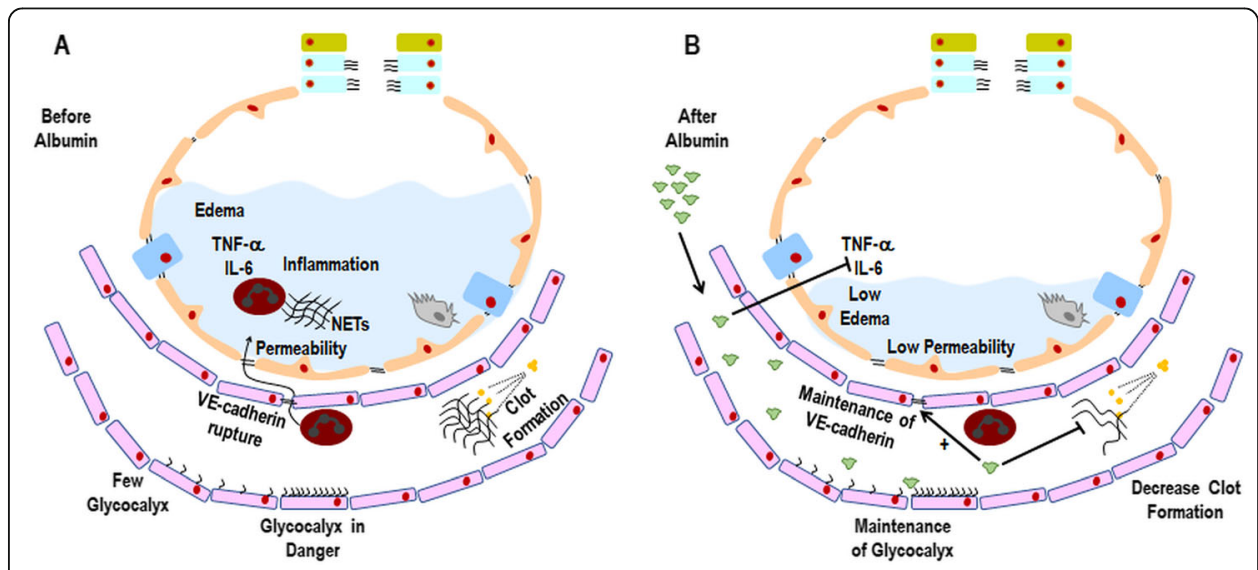

Fig. 3 a Before human albumin infusion. In ARDS, glycocalyx content is reduced and its function may be impaired depending on the stage of disease. Due to increased levels of pro-inflammatory mediators in the alveolar compartment, neutrophils are chemoattracted to the alveolar space, trespassing and causing damage to both endothelial cell junctions (e.g., VE-cadherin) and epithelial cell junctions (e.g., E-cadherin). Therefore, alveolar-capillary membrane damage increases, thus contributing to interstitial and alveolar edema. Activation of neutrophils in the alveolar space may promote the release of elastase and the production of neutrophil extracellular traps (NETs). Clot formation is increased, leading to aggregation of platelets into fibrin nets, which impair ventilation-perfusion ratio and decrease oxygenation. $\mathbf{b}$ After human albumin infusion. Human albumin is able to reduce levels of pro-inflammatory mediators in the alveolar compartment. Theoretically, this would reduce neutrophil attraction to the alveoli, thus reducing endothelial and epithelial cell damage and leading to decreased alveolar-capillary membrane permeability and lung edema. Human albumin is also able to maintain the glycocalyx connected to the luminal surface of endothelial cells. Finally, due to its heparin-like molecular structure, human albumin is able to reduce clot formation, which might improve ventilation-perfusion ratio and oxygenation 
endotoxin-induced ARDS, iso-oncotic albumin (4\%) reduced both lung and kidney damage [63]. A meta-analysis found that albumin improved oxygenation but did not affect mortality in ARDS [69].

Activation of the coagulation cascade is also involved in the pathophysiology of ARDS [70]. Albumin has the ability to inhibit platelet aggregation in a heparin-like manner, albeit with lower potency [71], due to structural similarities between the two. Therefore, in theory, albumin replacement may attenuate the coagulation cascade in ARDS when administered at the right time and dose. In critically ill patients, albumin administration resulted in prolonged activated partial thromboplastin time (APTT) [72]. In vitro studies using thromboelastometry measurements reported impaired clot formation in the hyper-oncotic compared to iso-oncotic albumin group [73]. The hypoalbuminemia often presents in cancer and critical illness may contribute to venous thromboembolism [73].

Albumin reduces lung edema and restores/maintains glycocalyx integrity in experimental ARDS [63]. Perhaps accordingly, iso-oncotic and hyper-oncotic albumin were associated with less lung edema compared with Ringer lactate in the same study [63]. Furthermore, albumin reduced glycocalyx damage in experimental models of ARDS induced by ischemia-reperfusion $[8,74,75]$ and hemorrhagic shock [76] (Fig. 3b).

\section{Conclusion}

ARDS is characterized by lung edema and damage to alveolar epithelium, endothelium, and extracellular matrix. Fluid administration is thus very challenging in these patients, since it can increase cardiac output and peripheral perfusion-thus improving tissue oxygenation and organ function-but may also result in serious adverse events. Fluid overload may be particularly dangerous in ARDS due to the possibility of worsening pulmonary edema.

Different methods have been used to assess the appropriateness of fluid infusion. However, clinical parameters frequently employed at bedside, such as mean arterial pressure, urine output, oxygen consumption, lactate, and central/mixed venous oxygen saturation, are actually of little use. Static monitoring parameters (e.g., central venous pressure) are unreliable markers of fluid responsiveness; thus, dynamic parameters (PLR, SVV, PPV, and EEO) have been recommended instead.

In short, fluids in ARDS must be administered cautiously, considering hemodynamic and perfusion status, oncotic and hydrostatic pressures, ARDS severity, fluid type, volume and infusion rate, and cardiac and renal function. To date, there is no published evidence to recommend any specific fluid composition over another in ARDS, and most physicians follow recommendations designed for sepsis instead. Further research is needed to help elucidate this issue with a view to improving clinical management of ARDS.

\footnotetext{
Abbreviations

ARDS: Acute respiratory distress syndrome; APTT: Activated partial thromboplastin time; BNP: B-type natriuretic peptide; CO: Cardiac output; CVP: Central venous pressure; EEO: End-expiratory occlusion test; GAGs: Glycosaminoglycans; Hcp: Hydrostatic capillary pressure; Hip: Hydrostatic interstitial pressure; IS: Interstitial space; NET: Neutrophil extracellular trap; Osg: Oncotic pressure; Oip: Oncotic interstitial pressure; Ocp: Oncotic capillary pressure; PLR: Passive leg raise test; PPV: Pulse pressure variation; SW: Stroke volume variation; TNF-a: Tumor necrosis factor alpha; TRAI L: TNF-related apoptosis-inducing ligand; $V_{T}$ : Tidal volume
} 


\section{About this supplement}

This article has been published as part of Intensive Care Medicine Experimental Volume 8 Supplement 1, 2020: Proceedings from the Fourth International Symposium on Acute Pulmonary Injury and Translation Research (INSPIRES IV). The full contents of the supplement are available at https://icm-experimental.springeropen.com/articles/ supplements/volume-8-supplement-1.

\section{Authors' contributions}

R.M., P.P., M.J.S., P.R.M.R., and P.L.S. wrote the manuscript and revised the final version. All authors read and approved the final version of the manuscript.

\section{Funding}

The Brazilian Council for Scientific and Technological Development (CNPq) funded research projects and scholarships for students, Rio de Janeiro State Research Foundation (FAPERJ) funded research projects and scholarships for students, Coordination for the Improvement of Higher Education Personnel (CAPES) funded publication costs and scholarships for students, the Department of Science and Technology—Brazilian Ministry of Health (DECIT/MS) funded research projects, and the National Institute of Science and Technology for Regenerative Medicine/CNPq funded research projects.

\section{Availability of data and materials}

Not applicable

\section{Ethics approval and consent to participate}

Not applicable

\section{Consent for publication}

Not applicable

\section{Competing interests}

None reported

\section{Author details}

'Laboratory of Pulmonary Investigation, Carlos Chagas Filho Biophysics Institute, Federal University of Rio de Janeiro, Centro de Ciências da Saúde, Avenida Carlos Chagas Filho, s/n, Bloco G-014, Ilha do Fundão, Rio de Janeiro, RJ 21941-902, Brazil. ${ }^{2}$ Department of Surgical Sciences and Integrated Diagnostics (DISC), University of Genoa, Genoa, Italy. ${ }^{3}$ San Martino Policlinico Hospital, IRCCS for Oncology and Neurosciences, Genoa, Italy. ${ }^{4}$ Department of Intensive Care, Academic Medical Centre, University of Amsterdam, Amsterdam, the Netherlands. ${ }^{5}$ Mahidol Oxford Tropical Medicine Research Unit (MORU), Mahidol University, Bangkok, Thailand. ${ }^{6}$ Nuffield Department of Medicine, University of Oxford, Oxford, UK.

Received: 14 July 2020 Accepted: 16 July 2020

Published: 18 December 2020

\section{References}

1. Matthay MA, Ware LB, Zimmerman GA (2012) The acute respiratory distress syndrome. J Clin Invest. [Research Support, N.I.H., Extramural Review] 122(8):2731-2740

2. Force ADT, Ranieri VM, Rubenfeld GD, Thompson BT, Ferguson ND, Caldwell E et al (2012) Acute respiratory distress syndrome: the Berlin Definition. JAMA. [Consensus Development Conference Research Support, N.I.H., Extramural Research Support, Non-U.S. Gov't] 307(23):2526-2533

3. Herwig MC, Tsokos M, Hermanns MI, Kirkpatrick CJ, Muller AM (2013) Vascular endothelial cadherin expression in lung specimens of patients with sepsis-induced acute respiratory distress syndrome and endothelial cell cultures. Pathobiology 80(5):245-251

4. Matthay MA, Zemans RL, Zimmerman GA, Arabi YM, Beitler JR, Mercat A et al (2019) Acute respiratory distress syndrome. Nat Rev Dis Primers 5(1):18

5. Bachofen M, Weibel ER (1982) Structural alterations of lung parenchyma in the adult respiratory distress syndrome. Clin Chest Med 3(1):35-56

6. Silversides JA, Major E, Ferguson AJ, Mann EE, MCAuley DF, Marshall JC et al (2017) Conservative fluid management or deresuscitation for patients with sepsis or acute respiratory distress syndrome following the resuscitation phase of critical illness: a systematic review and meta-analysis. Intensive Care Med 43(2):155-170

7. Malbrain M, Van Regenmortel N, Saugel B, De Tavernier B, Van Gaal PJ, Joannes-Boyau O et al (2018) Principles of fluid management and stewardship in septic shock: it is time to consider the four D's and the four phases of fluid therapy. Ann Intensive Care 8(1):66

8. Woodcock TE, Woodcock TM (2012) Revised Starling equation and the glycocalyx model of transvascular fluid exchange: an improved paradigm for prescribing intravenous fluid therapy. Br J Anaesth 108(3):384-394

9. Myburgh JA, Mythen MG (2013) Resuscitation fluids. N Engl J Med 369(25):2462-2463

10. Adamson RH, Lenz JF, Zhang X, Adamson GN, Weinbaum S, Curry FE (2004) Oncotic pressures opposing filtration across non-fenestrated rat microvessels. J Physiol 557(Pt 3):889-907

11. Pries AR, Secomb TW, Gaehtgens P (2000) The endothelial surface layer. Pflugers Arch 440(5):653-666

12. Chappell D, Bruegger D, Potzel J, Jacob M, Brettner F, Vogeser M et al (2014) Hypervolemia increases release of atrial natriuretic peptide and shedding of the endothelial glycocalyx. Crit Care 18(5):538

13. Berg S, Engman A, Hesselvik JF, Laurent TC (1994) Crystalloid infusion increases plasma hyaluronan. Crit Care Med 22(10):1563-1567 
14. van Golen RF, Reiniers MJ, Vrisekoop N, Zuurbier CJ, Olthof PB, van Rheenen J et al (2014) The mechanisms and physiological relevance of glycocalyx degradation in hepatic ischemia/reperfusion injury. Antioxid Redox Signal 21(7):1098-1118

15. Steppan J, Hofer S, Funke B, Brenner T, Henrich M, Martin E et al (2011) Sepsis and major abdominal surgery lead to flaking of the endothelial glycocalix. J Surg Res 165(1):136-141

16. Nieuwdorp M, Mooij HL, Kroon J, Atasever B, Spaan JA, Ince C et al (2006) Endothelial glycocalyx damage coincides with microalbuminuria in type 1 diabetes. Diabetes. 55(4):1127-1132

17. Johansson PI, Stensballe J, Rasmussen LS, Ostrowski SR (2011) A high admission syndecan-1 level, a marker of endothelial glycocalyx degradation, is associated with inflammation, protein C depletion, fibrinolysis, and increased mortality in trauma patients. Ann Surg 254(2):194-200

18. Zausig YA, Chappell D, Becker BF, Potschka D, Busse H, Nixdorf K et al (2013) The impact of crystalloidal and colloidal infusion preparations on coronary vascular integrity, interstitial oedema and cardiac performance in isolated hearts. Crit Care 17(5):R203

19. Rehm M, Bruegger D, Christ F, Conzen P, Thiel M, Jacob M et al (2007) Shedding of the endothelial glycocalyx in patients undergoing major vascular surgery with global and regional ischemia. Circulation. 116(17):1896-1906

20. Hofmann-Kiefer KF, Kemming Gl, Chappell D, Flondor M, Kisch-Wedel H, Hauser A et al (2009) Serum heparan sulfate levels are elevated in endotoxemia. Eur J Med Res 14:526-531

21. Nelson A, Berkestedt I, Schmidtchen A, Ljunggren L, Bodelsson M (2008) Increased levels of glycosaminoglycans during septic shock: relation to mortality and the antibacterial actions of plasma. Shock. 30(6):623-627

22. Sallisalmi M, Tenhunen J, Yang R, Oksala N, Pettila V (2012) Vascular adhesion protein-1 and syndecan-1 in septic shock. Acta Anaesthesiol Scand 56(3):316-322

23. National Heart L, Blood Institute Acute Respiratory Distress Syndrome Clinical Trials N, Wiedemann HP, Wheeler AP, Bernard GR, Thompson BT, et al. Comparison of two fluid-management strategies in acute lung injury. N Engl J Med 2006;354(24):2564-2575

24. Semler MW, Marney AM, Rice TW, Nian H, Yu C, Wheeler AP et al (2016) B-type natriuretic peptide, aldosterone, and fluid management in ARDS. Chest. 150(1):102-111

25. Jolley SE, Hough CL, Clermont G, Hayden D, Hou S, Schoenfeld D et al (2017) Relationship between race and the effect of fluids on long-term mortality after acute respiratory distress syndrome. Secondary Analysis of the National Heart, Lung, and Blood Institute Fluid and Catheter Treatment Trial. Ann Am Thorac Soc 14(9):1443-1449

26. Van der Mullen J, Wise R, Vermeulen G, Moonen PJ, Malbrain M (2018) Assessment of hypovolaemia in the critically ill. Anaesthesiol Intensive Ther 50(2):141-149

27. Weil MH, Henning RJ (1979) New concepts in the diagnosis and fluid treatment of circulatory shock. Thirteenth annual Becton, Dickinson and Company Oscar Schwidetsky Memorial Lecture. Anesth Analg 58(2):124-132

28. Monnet $X$, Teboul JL (2015) Passive leg raising: five rules, not a drop of fluid! Crit Care 19:18

29. Bentzer P, Griesdale DE, Boyd J, MacLean K, Sirounis D, Ayas NT (2016) Will this hemodynamically unstable patient respond to a bolus of intravenous fluids? JAMA 316(12):1298-1309

30. Mahjoub Y, Lejeune V, Muller L, Perbet S, Zieleskiewicz L, Bart F et al (2014) Evaluation of pulse pressure variation validity criteria in critically ill patients: a prospective observational multicentre point-prevalence study. $\mathrm{Br} J$ Anaesth 112(4):681-685

31. Monnet X, Marik PE, Teboul JL (2016) Prediction of fluid responsiveness: an update. Ann Intensive Care 6(1):111

32. Michard F, Teboul JL (2002) Predicting fluid responsiveness in ICU patients: a critical analysis of the evidence. Chest. [Review] 121(6):2000-2008

33. Jozwiak M, Depret F, Teboul JL, Alphonsine JE, Lai C, Richard C et al (2017) Predicting fluid responsiveness in critically ill patients by using combined end-expiratory and end-inspiratory occlusions with echocardiography. Crit Care Med 45(11):e1131-e11e8

34. Xu LY, Tu GW, Cang J, Hou JY, Yu Y, Luo Z et al (2019) End-expiratory occlusion test predicts fluid responsiveness in cardiac surgical patients in the operating theatre. Ann Transl Med 7(14):315

35. Depret F, Jozwiak M, Teboul JL, Alphonsine JE, Richard C, Monnet X (2019) Esophageal doppler can predict fluid responsiveness through end-expiratory and end-inspiratory occlusion tests. Crit Care Med 47(2):e96-e102

36. Guinot PG, Godart J, de Broca B, Bernard E, Lorne E, Dupont H (2014) End-expiratory occlusion manoeuvre does not accurately predict fluid responsiveness in the operating theatre. Br J Anaesth 112(6):1050-1054

37. Yonis H, Bitker L, Aublanc M, Perinel Ragey S, Riad Z, Lissonde F et al (2017) Change in cardiac output during Trendelenburg maneuver is a reliable predictor of fluid responsiveness in patients with acute respiratory distress syndrome in the prone position under protective ventilation. Crit Care 21(1):295

38. Chian CF, Tsao CM, Chen SJ, Chen ZF, Liaw WJ, Ka SM et al (2013) Hyperoncotic albumin attenuates lung and intestine injuries caused by peritonitis-induced sepsis in rats. J Surg Res 182(1):134-141

39. Powers KA, Kapus A, Khadaroo RG, He R, Marshall JC, Lindsay TF et al (2003) Twenty-five percent albumin prevents lung injury following shock/resuscitation. Crit Care Med 31(9):2355-2363

40. Morgan TJ (2013) The ideal crystalloid - what is 'balanced'? Curr Opin Crit Care 19(4):299-307

41. Robert Valeri C, Veech RL (2012) The unrecognized effects of the volume and composition of the resuscitation fluid used during the administration of blood products. Transfus Apher Sci 46(2):121-123

42. Hahn RG, Lyons G (2016) The half-life of infusion fluids: an educational review. Eur J Anaesthesiol 33(7):475-482

43. Chowdhury AH, Cox EF, Francis ST, Lobo DN (2012) A randomized, controlled, double-blind crossover study on the effects of 2-L infusions of $0.9 \%$ saline and plasma-lyte(R) 148 on renal blood flow velocity and renal cortical tissue perfusion in healthy volunteers. Ann Surg 256(1):18-24

44. Yunos NM, Bellomo R, Hegarty C, Story D, Ho L, Bailey M (2012) Association between a chloride-liberal vs chloriderestrictive intravenous fluid administration strategy and kidney injury in critically ill adults. Jama 308(15):1566-1572

45. McCluskey SA, Karkouti K, Wijeysundera D, Minkovich L, Tait G, Beattie WS (2013) Hyperchloremia after noncardiac surgery is independently associated with increased morbidity and mortality: a propensity-matched cohort study. Anesth Analg 117(2):412-421

46. Raghunathan K, Shaw A, Nathanson B, Sturmer T, Brookhart A, Stefan MS et al (2014) Association between the choice of IV crystalloid and in-hospital mortality among critically ill adults with sepsis*. Crit Care Med 42(7):1585-1591 
47. Young P, Bailey M, Beasley R, Henderson S, Mackle D, McArthur C et al (2015) Effect of a buffered crystalloid solution vs saline on acute kidney injury among patients in the intensive care unit: the SPLIT Randomized Clinical Trial. JAMA 314(16):1701-1710

48. Barea-Mendoza J, Chico-Fernandez M, Montejo-Gonzalez JC (2018) Balanced crystalloids versus saline in critically ill adults. N Engl J Med 378(20):1950-1951

49. Semler MW, Self WH, Rice TW (2018) Balanced crystalloids versus saline in critically ill adults. N Engl J Med 378(20):1951

50. Self WH, Semler MW, Wanderer JP, Wang L, Byrne DW, Collins SP et al (2018) Balanced crystalloids versus saline in noncritically ill adults. N Engl J Med 378(9):819-828

51. Finfer S, Myburgh J, Bellomo R (2018) Intravenous fluid therapy in critically ill adults. Nat Rev Nephrol 14(9):541-557

52. Wiedermann CJ, Joannidis M (2014) Albumin replacement in severe sepsis or septic shock. N Engl J Med. [Comment Letter] 371(1):83

53. Claus RA, Sossdorf M, Hartog C (2010) The effects of hydroxyethyl starch on cultured renal epithelial cells. Anesth Analg 110(2):300-301

54. Wiedermann CJ, Joannidis M (2014) Accumulation of hydroxyethyl starch in human and animal tissues: a systematic review. Intensive Care Med 40(2):160-170

55. Vincent JL, Russell JA, Jacob M, Martin G, Guidet B, Wernerman J et al (2014) Albumin administration in the acutely ill: what is new and where next? Crit Care 18(4):231

56. Martin GS, Mangialardi RJ, Wheeler AP, Dupont WD, Morris JA, Bernard GR (2002) Albumin and furosemide therapy in hypoproteinemic patients with acute lung injury. Crit Care Med. [Clinical Trial Randomized Controlled Trial Research Support, Non-U.S. Gov't Research Support, U.S. Gov't, P.H.S.] 30(10):2175-2182

57. Fanali G, di Masi A, Trezza V, Marino M, Fasano M, Ascenzi P (2012) Human serum albumin: from bench to bedside. Mol Asp Med 33(3):209-290

58. Ulldemolins M, Roberts JA, Rello J, Paterson DL, Lipman J (2011) The effects of hypoalbuminaemia on optimizing antibacterial dosing in critically ill patients. Clin Pharmacokinet 50(2):99-110

59. Demling RH (1986) Effect of plasma and interstitial protein content on tissue edema formation. Curr Stud Hematol Blood Transfus 53:36-52

60. Zoellner H, Hofler M, Beckmann R, Hufnagl P, Vanyek E, Bielek E et al (1996) Serum albumin is a specific inhibitor of apoptosis in human endothelial cells. J Cell Sci 109(Pt 10):2571-2580

61. Pinheiro CC, Rayol P, Gozzani L, Reis LM, Zampieri G, Dias CB et al (2014) The relationship of angiogenic factors to maternal and neonatal manifestations of early-onset and late-onset preeclampsia. Prenat Diagn 34(11):1084-1092

62. Gong H, Rehman J, Tang H, Wary K, Mittal M, Chaturvedi P et al (2015) HIF2alpha signaling inhibits adherens junctional disruption in acute lung injury. J Clin Invest. [Research Support, N.I.H., Extramural Research Support, Non-U.S. Gov't] 125(2):652-664

63. Mendes RS, Oliveira MV, Padilha GA, Rocha NN, Santos CL, Maia LA et al (2019) Effects of crystalloid, hyper-oncotic albumin, and iso-oncotic albumin on lung and kidney damage in experimental acute lung injury. Respir Res 20(1):155

64. Alexander JS, Alexander BC, Eppihimer LA, Goodyear N, Haque R, Davis CP et al (2000) Inflammatory mediators induce sequestration of VE-cadherin in cultured human endothelial cells. Inflammation. 24(2):99-113

65. Saffarzadeh M, Juenemann C, Queisser MA, Lochnit G, Barreto G, Galuska SP et al (2012) Neutrophil extracellular traps directly induce epithelial and endothelial cell death: a predominant role of histones. PLoS One 7(2):e32366

66. Hogner K, Wolff T, Pleschka S, Plog S, Gruber AD, Kalinke U et al (2013) Macrophage-expressed IFN-beta contributes to apoptotic alveolar epithelial cell injury in severe influenza virus pneumonia. PLoS Pathog 9(2):e1003188

67. Neuhaus W, Schick MA, Bruno RR, Schneiker B, Forster CY, Roewer N et al (2012) The effects of colloid solutions on renal proximal tubular cells in vitro. Anesth Analg 114(2):371-374

68. Kremer H, Baron-Menguy C, Tesse A, Gallois Y, Mercat A, Henrion D et al (2011) Human serum albumin improves endothelial dysfunction and survival during experimental endotoxemia: concentration-dependent properties. Crit Care Med 39(6):1414-1422

69. Uhlig C, Silva PL, Deckert S, Schmitt J, de Abreu MG (2014) Albumin versus crystalloid solutions in patients with the acute respiratory distress syndrome: a systematic review and meta-analysis. Crit Care 18(1):R10

70. Matthay MA, Zimmerman GA (2005) Acute lung injury and the acute respiratory distress syndrome: four decades of inquiry into pathogenesis and rational management. Am J Respir Cell Mol Biol. [Research Support, N.I.H., Extramural Research Support, U.S. Gov't, P.H.S. Review] 33(4):319-327

71. Jorgensen KA, Stoffersen E (1980) On the inhibitory effect of albumin on platelet aggregation. Thromb Res 17(1-2):13-18

72. Bellomo R, Morimatsu H, Presneill J, French C, Cole L, Story D et al (2009) Effects of saline or albumin resuscitation on standard coagulation tests. Crit Care Resusc 11(4):250-256

73. Paar M, Rossmann C, Nusshold C, Wagner T, Schlagenhauf A, Leschnik B et al (2017) Anticoagulant action of low, physiologic, and high albumin levels in whole blood. PLoS One 12(8):e0182997

74. Jacob M, Bruegger D, Rehm M, Welsch U, Conzen P, Becker BF (2006) Contrasting effects of colloid and crystalloid resuscitation fluids on cardiac vascular permeability. Anesthesiology. 104(6):1223-1231

75. Jacob M, Paul O, Mehringer L, Chappell D, Rehm M, Welsch U et al (2009) Albumin augmentation improves condition of guinea pig hearts after $4 \mathrm{hr}$ of cold ischemia. Transplantation. 87(7):956-965

76. Kozar RA, Peng Z, Zhang R, Holcomb JB, Pati S, Park P et al (2011) Plasma restoration of endothelial glycocalyx in a rodent model of hemorrhagic shock. Anesth Analg 112(6):1289-1295

\section{Publisher's Note}

Springer Nature remains neutral with regard to jurisdictional claims in published maps and institutional affiliations. 